\title{
Deleted in Breast Cancer 1 as a Novel Prognostic Biomarker for Digestive System Cancers: A Meta-Analysis
}

\author{
Jingting Liu ${ }^{*}$, Chunyan Meng ${ }^{2}$, Changcan Li³ ${ }^{3}$ Kaifeng Tang², Hongchao Tang², Jianhua Liao ${ }^{2}$ \\ 1. Department of Emergency, Sir Run Run Shaw Hospital, Zhejiang University School of Medicine, 3 Qingchun East Road, Hangzhou, Zhejiang, 310020, China \\ 2. Department of General Surgery, Zhejiang Hospital, 12 Lingyin Road, Zhejiang 310013, China \\ 3. Department of General Surgery, Shanghai General Hospital, Shanghai Jiao Tong University School of Medicine, 100 Haining Road, Shanghai 200080, China. \\ "These authors have contributed equally to this work.
}

$\square$ Corresponding author: Jianhua Liao, Mailing address: Department of General Surgery, Zhejiang Hospital, 12 Lingyin Road, Zhejiang 310013, China. Work Telephone Numbers: 86-15000082369; Fax Numbers: 86-0571-87987373-5076; E-mail: ljhsywzh@163.com; 452103619@alumni.sjtu.edu.cn

(c) Ivyspring International Publisher. This is an open access article distributed under the terms of the Creative Commons Attribution (CC BY-NC) license (https://creativecommons.org/licenses/by-nc/4.0/). See http://ivyspring.com/terms for full terms and conditions.

Received: 2018.04.27; Accepted: 2019.01.19; Published: 2019.03.03

\begin{abstract}
Deleted in Breast Cancer 1 (DBCl/CCAR2) is a regulatory protein involved in cell survival and cancer progression. Herein, we focused on summarizing the overall prognostic value of $\mathrm{DBCl}$ for digestive system cancers. Therefore, we conducted a meta-analysis based on 9 studies with 2391 patients to generated combined hazard ratios (HR) or odds ratio (OR) with its $95 \%$ confidence intervals $(\mathrm{Cl})$ for overall survival $(\mathrm{OS})$ and clinicopathological features. Positive $\mathrm{DBCl}$ expression was significantly associated with poor OS of digestive system cancers (pooled $H R=1.650,95 \%$ $\mathrm{Cl}=1.087-2.504, \mathrm{P}<0.019)$. Stratified analysis also verified the potential prognostic prediction of $\mathrm{DBCl}$ in some subgroups, such as digestive tract cancers (pooled $\mathrm{HR}=1.685,95 \% \mathrm{Cl}=1.013-2.802$, $\mathrm{P}=0.044$ ), univariate analysis method (pooled $\mathrm{HR}=2.077,95 \% \mathrm{Cl}=1.221-3.533, \mathrm{P}=0.007$ ), publication date within five years (pooled $\mathrm{HR}=1.609,95 \% \mathrm{Cl}=1.097-2.358, \mathrm{P}=0.015$ ), study sample size smaller than 200 (pooled $\mathrm{HR}=2.304,95 \% \mathrm{Cl}=1.716-3.093, \mathrm{P}<0.001$ ) and cutoff value for positive tumor cells more than $50 \%$ (pooled $\mathrm{HR}=1.944,95 \% \mathrm{Cl}=1.479-2.556, \mathrm{P}<0.001$ ). Additionally, in terms of the association between $\mathrm{DBCl}$ expression and clinicopathological characteristics, DBCl expression was correlated to age (pooled $\mathrm{OR}=0.596,95 \% \mathrm{Cl}=0.467-0.761, \mathrm{P}<0.001$ ), WHO classification (pooled $\mathrm{OR}=3.780,95 \% \mathrm{Cl}=2.303-6.205, \mathrm{P}<0.001$ ), Lauren classification (pooled $\mathrm{OR}=2.000$, $95 \% \mathrm{Cl}=1.492-2.680, \mathrm{P}<0.001$ ), and lymph node metastasis (pooled $\mathrm{OR}=0.405,95 \% \mathrm{Cl}=0.203-0.806$, $\mathrm{P}=0.010$ ). In conclusion, $\mathrm{DBCl}$ could not only be an independent prognostic factor for survival of patients with digestive system cancer, but might also be a novel target for cancer therapy.
\end{abstract}

Key words: Deleted in Breast Cancer 1, digestive system cancer, prognosis, biomarker, meta-analysis

\section{Introduction}

Cancer is a leading cause of disease-related death worldwide. Much of the rising burden is due to the growth and aging of the population. Besides, with the change of people's diet structure and lifestyle, the digestive system cancers, composing many complicated organs and unintelligible anatomy, cause approximately 3.2 million deaths per year, which have become one of the most terrible threats for human health [1-2]. To date, the incidence of esophageal squamous cell carcinoma (ESCC), gastric cancer (GC), hepatocellular carcinoma (HCC), and colorectal cancer (CRC) are still increasing, and ranking among the top causes of cancer-related death worldwide, especially in Eastern Asia (particularly in Korea, Japan, and China)[2]. Though advances in prevention, diagnosis, surgical procedure and adjuvant therapy have been rapidly made, overall prognosis and survival of patients with digestive 
system cancers have not improved satisfactorily. Currently, TNM stage, lymph node (LN) invasion, distant metastasis and recurrence are well-known predictors of patient's prognosis after medical treatment [3-5]. Otherwise, hexokinase 2[6] and octamer-binding transcription factor 4[7] were shown to be related to post-operation prognosis. While, it is still hard to explain the individual differences in patient's prognosis, hence, there may be additional markers involved in prognostic information of digestive system cancers, thereby helping patients to avoid enslaving to these digestive neoplasms.

Deleted in breast cancer-1/Cell Cycle and Apoptosis Regulator 2 (DBC1/CCAR2), as a new transcriptional co-activator for nuclear receptors and other transcription factors, is initially identified homozygously delete in human chromosome 8p21 in breast cancer, as well as a functional regulator of various proteins[8-9]. As the name implies, the characterization of $\mathrm{DBC} 1$ originally focused on its functions in breast cancer, which could serve as a potential therapeutic biomarker in cancer diagnose and treatment. Although, studies found that DBC1 was over-expressed in breast cancers and predicted a poor outcome [10], much of the convincing studies gradually reported that DBC1 regulates SIRT1 activity and the transcription of BRCA1, impacts the anoikis via the IKK- $\beta / N F-\kappa B$ signaling pathway, inhibits SIRT1-dependent cell survival through the p53 pathway, promotes estrogen-independent proliferation and modulates of estrogen receptor alpha expression and hormone-independent survival in breast cancer[11-15], which suggested the role of $\mathrm{DBC} 1$, as a tumor suppressor or oncogenic protein, is still controversial in cell survival. However, despite the identification of $\mathrm{DBC} 1$ in breast cancer, $\mathrm{DBC} 1$ has been reported in various cancers, especially in the digestive system cancers. Notably, DBC1 promotes anoikis resistance in GC cells by regulating NF- $\mathrm{KB}$ activity, regulates CRC progression by $\beta$-cateninPROX1 signaling axis [16-17]. Furthermore, the abnormal expression of $\mathrm{DBC} 1$ has found in various digestive system cancers, e.g. ESCC, GC, CRC, HCC, which was associated with cancer progression and poor prognosis $[4,18-20]$. In obvious contrast, DBC1 was correlated with better survival and good prognostic factors including lower histologic grade, lower pathologic $\mathrm{T}$ and $\mathrm{N}$ stage, and absence of lymphatic invasion of GC according to the study by Youngran et al [21]. Meanwhile, DBC1 lost its relevance and prognostic value in CRC [22]. The paradoxical results lead to an unresolved issue of the relationship between DBC1 expression and the clinical outcome of cancer patients. Thus, the prognostic value of $\mathrm{DBC} 1$ in digestive system cancers needs to be confirmed by systematic analyses. Therefore, on the basis of a comprehensive search of the relevant literature, we conducted this meta-analysis to evaluate the prognostic value of $\mathrm{DBC} 1$ in digestive system cancers.

\section{Materials and Methods}

\section{Search strategy and study selection}

A systematic computer-aided literature search PubMed, PMC, Elsevier, Springer, Wiley, EBSCO, ScienceDirect, Web of Science was conducted (last updated in July 2018) by using the following terms: "(DBC1 or deleted in breast cancer 1) AND (cancer or tumor or malignancy or neoplasm or carcinoma) AND (prognosis or prognostic or survival or outcome)". We also screened the lists of the references in relevant literatures and applied alternative terms (Cell Cycle and Apoptosis Regulator 2 or CCAR2) for comprehensive search to prevent missed. The meta-analysis was in accordance with the reporting checklist as part of the preferred reporting items for systematic reviews and meta-analyses statement [23]. Languages of the researched literature were limited to English.

\section{Inclusion and exclusion criteria}

Publications were recruited in this meta-analysis, when they fit all of the following criteria: (1) evaluating the relationship between DBC1 expression and clinical parameters and overall survival (OS) in digestive system cancer patients using a retrospective design; (2) examining DBC1 protein expression in tumor tissue; (3) patients were grouped according to the DBC1 positive and DBC1 negative; (4) complete definition of the cutoff value; (5) having the hazard rations (HRs) and 95\% confidence intervals (CIs) information for estimating the survival outcomes; (6) studies with more than 100 patients; (7) patients were received surgical treatment, without history of prior adjuvant chemotherapy or additional re-operation after surgery; (8) Correct statistical and experimental methods. (9) Having specific and effective anti-DBC1. We excluded the following studies: letters, editorials, meeting abstracts, case reports, and reviews.

\section{Data extraction and quality assessment}

Data extracted from each study included the first author, publication date, country, age, recruitment time, sample size, cancer type, detection method, follow-up period, cutoff values, analysis method, survival outcomes, HR estimation, quality scores, and necessary clinical characteristics. Each literature was read and extracted independently by 2 clinicians in a blinded fashion. Any disagreements were resolved by scientific discussion. The Newcastle-Ottawa Scale 
(NOS) was applied to assess the included studies [24]. As following categories: selection, comparability, and exposure. Briefly, the total score of NOS was the sum of the scores for the three categories. Base on the scores, we considered studies as high quality if the score $>6$.

\section{Statistical analysis}

All the tests were performed using STATA 14.0 software (STATA Corporation, College Station, Texas, USA). Two-sided tests were used in all the analysis. The odds ratios (ORs) and their corresponding 95\% CI were combined to estimate the effect of the correlation between DBC1 expression and clinicopathological features (i.e., gender, age, TNM stage, tumor invasion, venous invasion, LN metastasis, histologic grade, WHO classification, distant metastasis) by the pooled analysis. HRs with the corresponding 95\% CIs were used to estimate the strength of the association between DBC1 expression and clinical prognosis of cancer patients through Z-test. And HRs and the corresponding $95 \%$ CIs by multivariate analysis in original data were preferential subjected in the analysis models. Otherwise, subgroups were also conducted in such way to acquire the pooled HRs. Heterogeneity between studies was quantified by

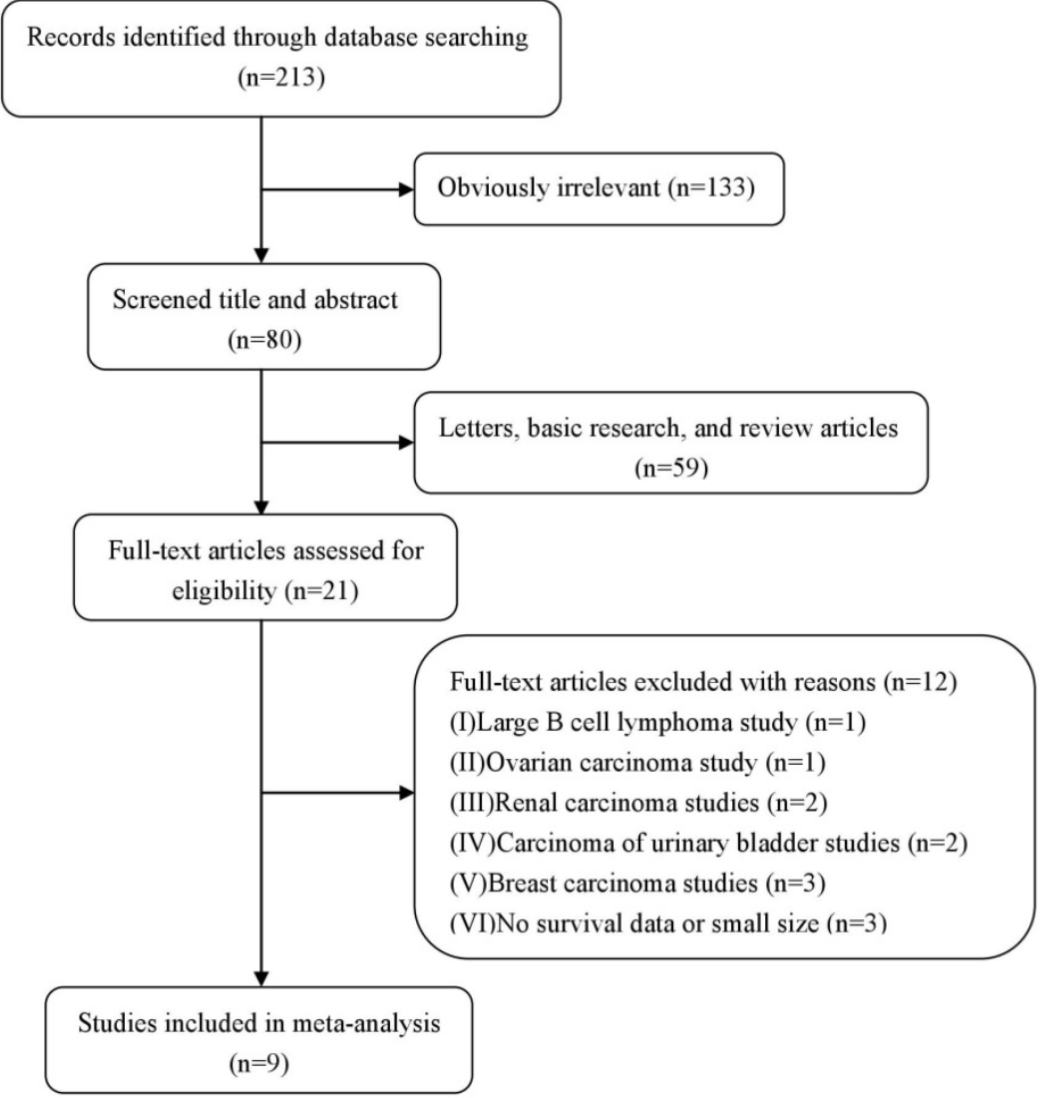

Figure 1. The flow diagram of study selection and exclusion process in the meta-analysis
Chi-squared test and $\mathrm{I}^{2}$ statistics. The random effect models was used to assessing the pooled estimates, when the Chi-squared test of $\mathrm{P}<0.10$ or $\mathrm{I}^{2}>50 \%$, while the fixed effect model was applied in the absence of heterogeneity. Cumulative meta-analysis was performed to show the trend in the estimated effect. Sensitivity analysis was carried out by sequentially omitting individual study to validate the stability of the pooled outcomes based on the overall HR estimate of OS. Meta-regression analysis was performed to investigate the potential source of heterogeneity among studies. Egger's regression plot and Begg's test were used to evaluate the risk of publication bias. $\mathrm{P}<0.05$ was considered statistically significant.

\section{Results}

\section{Characteristics of the included studies}

The precise selection process of literature search is shown in Figure 1. A total of 213 relevant publications were prospectively identified, after careful examination of the titles and abstracts from each literature, 192 studies were excluded because they were letters, basic research, review articles, or obvious beyond the inclusion criteria. And, 12 of them were further excluded (excluded for large B cell lymphoma study [n=1], ovarian carcinoma study $[\mathrm{n}=1]$, renal carcinoma studies [n=2], carcinoma of urinary bladder studies $[\mathrm{n}=2]$, breast carcinoma studies $[n=3]$, and no survival data or small size $[\mathrm{n}=3]$ ). Therefore, 9 eligible studies published from 2009 to 2017 were included. A total of 2391 patients from China, Japan, Korea were diagnosed with digestive system cancers, including ESCC [18], HCC [20, 25], GC $[3,5,19,21]$, and CRC[4,22]. The patients were recruited from 1982 to 2011, and DBC1 expression was evaluated by immunohistochemistry (IHC) method in these 9 included studies. Cutoff values for positive DBC1 expression were also well definite in all included studies. 8 studies provided the follow up end point, and 5 studies were grouped patients by age 60.7 studies provided the HRs for OS and the corresponding CIs through multivariate analysis, while 8 studies were calculated from univariate analysis. All studies were considered as the high quality literature after figure up the NOS scores. The detail information is summarized in table 1. 
Table 1. Main characteristics of studies included in meta-analysis

\begin{tabular}{|c|c|c|c|c|c|c|c|c|c|c|c|c|}
\hline Author & Year & $\begin{array}{l}\text { Study } \\
\text { region }\end{array}$ & Age & $\begin{array}{l}\text { Recruitm } \\
\text { ent time }\end{array}$ & $\begin{array}{l}\text { Sample } \\
\text { size }\end{array}$ & $\begin{array}{l}\text { Cancer } \\
\text { type }\end{array}$ & $\begin{array}{l}\text { Detection } \\
\text { method }\end{array}$ & $\begin{array}{l}\text { Follow up } \\
\text { period }\end{array}$ & $\begin{array}{l}\text { Cutoff scores } \\
\text { (High/Low) }\end{array}$ & Analysis method & $\begin{array}{l}\text { OS, HR } \\
\text { estimation }\end{array}$ & $\begin{array}{l}\text { Quality } \\
\text { score }\end{array}$ \\
\hline $\begin{array}{l}\text { EunJung } \\
\text { Cha }\end{array}$ & 2009 & Korea & $\begin{array}{l}<60: 53 \\
\geq 60: 124\end{array}$ & $1997-2005$ & 177 & GC & $\mathrm{IHC}$ & up to 2008.3 & $\begin{array}{l}\text { positive if } 30 \% \text { or } \\
\text { more of the } \\
\text { tumor cells }\end{array}$ & $\begin{array}{l}\text { Univariate/ } \\
\text { Multivariate analysis }\end{array}$ & $\begin{array}{l}3.334 \\
(1.557-7.139)\end{array}$ & 8 \\
\hline $\begin{array}{l}\text { SeokHyung } \\
\text { Kim }\end{array}$ & 2012 & Korea & $\begin{array}{l}<65: 127 \\
\geq 65: 38\end{array}$ & NS & 165 & ESCC & IHC & NS & Score $\geq 8^{\#}$ & $\begin{array}{l}\text { Univariate/ } \\
\text { Multivariate analysis }\end{array}$ & $\begin{array}{l}2.830 \\
(1.680-4.767)\end{array}$ & 7 \\
\hline $\begin{array}{l}\text { Youngran } \\
\text { Kang }\end{array}$ & 2012 & Korea & $\begin{array}{l}<60: 213 \\
\geq 60: 239\end{array}$ & 2002-2005 & 452 & GC & IHC & $\begin{array}{l}53.3(3-83) \\
\text { months }\end{array}$ & $\begin{array}{l}\text { positive if } 30 \% \text { or } \\
\text { more of the } \\
\text { tumor cells }\end{array}$ & Multivariate analysis & $\begin{array}{l}0.581 \\
(0.381-0.886)\end{array}$ & 8 \\
\hline $\begin{array}{l}\text { Wonkyung } \\
\text { Jung }\end{array}$ & 2013 & Korea & $\begin{array}{l}<65: 186 \\
\geq 65: 163\end{array}$ & 2002-2009 & 349 & $\mathrm{CC}$ & IHC & $\begin{array}{l}\text { mean } 55.3 \\
\text { months }\end{array}$ & $\begin{array}{l}\text { positive if } 70 \% \text { or } \\
\text { more of the } \\
\text { tumor cells }\end{array}$ & Univariate analysis & $\begin{array}{l}1.396 \\
(0.818-2.381)\end{array}$ & 7 \\
\hline $\begin{array}{l}\text { Yongguo } \\
\text { Zhang }\end{array}$ & 2014 & China & $\begin{array}{l}<60: 87 \\
\geq 60: 99\end{array}$ & 2004-2006 & 186 & $\mathrm{CC}$ & IHC & at least 5 years & Score $\geq 9 \#$ & $\begin{array}{l}\text { Univariate/ } \\
\text { Multivariate analysis }\end{array}$ & $\begin{array}{l}3.44 \\
(1.36-8.69)\end{array}$ & 8 \\
\hline $\begin{array}{l}\text { Akira } \\
\text { Noguchi }\end{array}$ & 2014 & Japan & $\begin{array}{l}<65: 319 \\
\geq 65: 238\end{array}$ & 1999-2002 & 557 & GC & IHC & $\begin{array}{l}69(6-142) \\
\text { months }\end{array}$ & $\begin{array}{l}\text { positive if } 25 \% \text { or } \\
\text { more of the } \\
\text { tumor cells }\end{array}$ & $\begin{array}{l}\text { Univariate/ } \\
\text { Multivariate analysis }\end{array}$ & $\begin{array}{l}0.962 \\
(0.682-1.358)\end{array}$ & 8 \\
\hline Jun Sang Bae & 2015 & Korea & $\begin{array}{l}<60: 60 \\
\geq 60: 127\end{array}$ & 1997-2005 & 187 & GC & IHC & up to 2011.12 & $\begin{array}{l}\text { positive if } 30 \% \text { or } \\
\text { more of the } \\
\text { tumor cells * }\end{array}$ & Univariate analysis & $\begin{array}{l}2.234 \\
(1.403-3.556)\end{array}$ & 7 \\
\hline Sang Yun Ha & 2016 & Korea & $\begin{array}{l}\leq 55: 125 \\
>55: 74\end{array}$ & 2000-2006 & 199 & $\mathrm{HCC}$ & IHC & $\begin{array}{l}\text { 119.1(24.0-151. } \\
\text { 4) months }\end{array}$ & $\begin{array}{l}\text { positive if } 50 \% \text { or } \\
\text { more of the } \\
\text { tumor cells }\end{array}$ & $\begin{array}{l}\text { Univariate/ } \\
\text { Multivariate analysis }\end{array}$ & $\begin{array}{l}1.108 \\
(0.561-2.186)\end{array}$ & 8 \\
\hline Changcan Li & 2017 & China & $\begin{array}{l}<60: 59 \\
\geq 60: 60\end{array}$ & 2007-2009 & 119 & $\mathrm{HCC}$ & IHC & at least 4 years & Score $\geq 7 \#$ & $\begin{array}{l}\text { Univariate/ } \\
\text { Multivariate analysis }\end{array}$ & $\begin{array}{l}2.183 \\
(1.211-3.937)\end{array}$ & 8 \\
\hline
\end{tabular}

* Cells showed moderate or strong staining intensity; \# The score for intensity was multiplied by the score for extent of staining; GC gastric cancer; ESCC esophageal squamous cell carcinoma; CRC colorectal cancer; HCC hepatocellular carcinoma; IHC Immunohistochemical; NS data were not shown; OS overall survival; HR hazard ration

Table 2. Meta-analysis of $\mathrm{DBCl}$ overexpression and prognosis in digestive system cancers

\begin{tabular}{|c|c|c|c|c|c|c|}
\hline Categories & $\begin{array}{l}\text { Studies } \\
\text { (patients) }\end{array}$ & HR $(95 \%$ CI) & $I^{2}(\%)$ & $\mathbf{P}_{\mathbf{h}}$ & $\mathbf{Z}$ & $P$ \\
\hline OS & $9(2391)$ & $1.650(1.087-2.504)^{\mathrm{R}}$ & 81.6 & $<0.001$ & 2.35 & 0.019 \\
\hline \multicolumn{7}{|l|}{ Cancer type } \\
\hline $\begin{array}{l}\text { Digestive tract } \\
\text { cancer }\end{array}$ & $7(2073)$ & $1.685(1.013-2.802)^{\mathrm{R}}$ & 85.2 & $<0.001$ & 2.01 & 0.044 \\
\hline GC & $4(1373)$ & $1.365(0.684-2.723)^{\mathrm{R}}$ & 88.6 & $<0.001$ & 0.88 & 0.378 \\
\hline CRC & $2(535)$ & $2.017(0.846-4.808)^{\mathrm{R}}$ & 63.3 & 0.099 & 1.58 & 0.113 \\
\hline $\mathrm{HCC}$ & $2(318)$ & $1.590(0.819-3.087)^{\mathrm{R}}$ & 54.2 & 0.140 & 1.37 & 0.171 \\
\hline \multicolumn{7}{|c|}{ Analysis method } \\
\hline $\begin{array}{l}\text { Multivariate } \\
\text { analysis }\end{array}$ & $7(1855)$ & $1.631(0.959-2.776)^{\mathrm{R}}$ & 84.5 & 0.001 & 1.80 & 0.071 \\
\hline $\begin{array}{l}\text { Univariate } \\
\text { analysis }\end{array}$ & 8(1939) & $2.077(1.221-3.533)^{\mathrm{R}}$ & 87.6 & $<0.001$ & 2.70 & 0.007 \\
\hline \multicolumn{7}{|l|}{ Publication date } \\
\hline$\leq 5$ years & $6(1597)$ & $1.609(1.097-2.358)^{\mathrm{R}}$ & 65.7 & 0.012 & 2.44 & 0.015 \\
\hline$>5$ years & $3(794)$ & $1.723(0.520-5.708)^{\mathrm{R}}$ & 93.0 & $<0.001$ & 0.89 & 0.373 \\
\hline \multicolumn{7}{|l|}{ Size } \\
\hline$<200$ & $6(1033)$ & $2.304(1.716-3.093)^{\mathrm{F}}$ & 25.6 & 0.242 & 6.58 & $<0.001$ \\
\hline$>200$ & $3(1358)$ & $0.903(0.572-1.426)^{\mathrm{R}}$ & 70.8 & 0.033 & 0.44 & 0.662 \\
\hline \multicolumn{7}{|l|}{ Cutoff value } \\
\hline $\begin{array}{l}\text { Positive tumor } \\
\text { cells }>50 \%\end{array}$ & $5(1018)$ & $1.944(1.479-2.556)^{\mathrm{F}}$ & 48.0 & 0.103 & 4.77 & $<0.001$ \\
\hline Others & $4(1373)$ & $1.365(0.684-2.723)^{\mathrm{R}}$ & 88.6 & $<0.001$ & 0.88 & 0.378 \\
\hline \multicolumn{7}{|c|}{ Research region } \\
\hline China & $2(305)$ & $2.489(1.513-4.093)^{\mathrm{F}}$ & 0.0 & 0.417 & 3.59 & $<0.001$ \\
\hline Others & $7(2086)$ & $1.472(0.919-2.356)^{\mathrm{R}}$ & 83.7 & $<0.001$ & 1.61 & 0.107 \\
\hline $\begin{array}{l}\text { OS overall survi } \\
\text { heterogeneity ba } \\
\text { GC gastric cance } \\
\text { HRs were derive }\end{array}$ & val; HR haz & ration; CI confidenc & interva & $1 ; P_{h} P-y$ & Jo & $\begin{array}{l}\text { or } \\
\text { n Z test; } \\
\text { pooled } \\
\text { rom }\end{array}$ \\
\hline
\end{tabular}

\section{Survival analysis and prognosis significance of DBCl expression in digestive system cancers}

The combined analysis of included datasets is shown in Table 2. A statistically significant difference was found in DBC1 expression between OS (pooled $\mathrm{HR}=1.650,95 \% \quad \mathrm{CI}=1.087-2.504, \quad \mathrm{P}=0.019$ ) (Fig.2), indicating $\mathrm{DBC1}$ overexpression had relatively reduced OS in patients with digestive system cancers. Additionally, significant difference also found in digestive tract cancers (pooled $\mathrm{HR}=1.685$, 95\% $\mathrm{CI}=1.013-2.802, \mathrm{P}=0.044)$, but no differences were obtained in the subgroup analysis which was conducted by cancer type. Specifically, the prognosis in patients with GC (pooled $\mathrm{HR}=1.365$, 95\% $\mathrm{CI}=0.684-2.723, \mathrm{P}=0.378$ ), $\mathrm{CRC}$ (pooled $\mathrm{HR}=2.017$, 95\% CI $=0.846-4.808, \quad \mathrm{P}=0.113$ ), $\quad$ or $\mathrm{HCC}$ (pooled $\mathrm{HR}=1.590,95 \% \mathrm{CI}=0.819-3.087, \mathrm{P}=0.171$ ) were no correlation with DBC1 expression. In addition, we conducted subgroup analysis according to analysis methods, the results revealed that DBC1 expression level significantly lead to the poor OS in patients with digestive system cancers in univariate analysis (pooled HR=2.077, 95\% CI=1.221-3.533, $\mathrm{P}=0.007$ ), but not in multivariate analysis (pooled $\mathrm{HR}=1.631$, $95 \% \mathrm{CI}=0.959-2.776, \mathrm{P}=0.071$ ). The stratification according to publication date also verified the association between $\mathrm{DBC} 1$ expression and patients' OS in last five years studies (pooled $\mathrm{HR}=1.609,95 \% \mathrm{CI}=1.097-2.358, \mathrm{P}$ $=0.015)$. And, in the analysis stratified by size of sample, DBC1 expression level was found to be significantly associated with OS of patients in studies with sample size smaller than 200 (pooled HR=2.304, 95\% CI=1.716-3.093, $\quad \mathrm{P}<0.001)$. Furthermore, this association still existed in cutoff value (positive tumor cells $>50 \%$ ), and research region (China) subgroups 
(pooled $\mathrm{HR}=1.944,95 \% \mathrm{CI}=1.479-2.556, \mathrm{P}<0.001$; pooled $\mathrm{HR}=2.489, \quad 95 \% \mathrm{CI}=1.513-4.093, \quad \mathrm{P}<0.001$, respectively). However, there were no significant differences in the other corresponding subgroups.

To assess whether there is the heterogeneity of DBC1 among the included studies, we analyzed the heterogeneity through the $\mathrm{Q}$ statistic. As illustrated in Table 2, we performed a random-effects model to estimate the overall $\mathrm{HR}$ for OS for its extreme heterogeneity $\left(\mathrm{I}^{2}=81.6 \%, \mathrm{P}_{\mathrm{h}}<0.001\right)$. Actually, even if we use the stratified analysis to assess the source of heterogeneity based on the subgroups of cancer type, detection method, analysis method, publication date, sample size, cutoff value, and study region, the heterogeneity was seem to be still remarkable.

\section{Association between DBCl expression and clinicopathological characteristics of digestive system cancers}

Results are reported in Table 3. The pooled estimates showed that DBC1 expression was correlated to age (pooled $\mathrm{OR}=0.596,95 \% \mathrm{CI}=0.467-0.761, \mathrm{P}<0.001$ ),
WHO classification (pooled OR $=3.780,95 \% \mathrm{CI}=2.303$ 6.205, $\mathrm{P}<0.001$ ), Lauren classification (pooled $\mathrm{OR}=$ $2.000,95 \% \mathrm{CI}=1.492-2.680, \mathrm{P}<0.001)$, and LN metastasis (pooled $\mathrm{OR}=0.405,95 \% \mathrm{CI}=0.203-0.806, \mathrm{P}=0.010$ ), indicating that overexpression of DBC1 was more likely to be found in older patients with intestinaltype or tubular carcinoma, and played a role in tumor aggressiveness. Furthermore, no significant association was found between DBC1 and a number of clinicopathological characteristics, including gender (pooled $\mathrm{OR}=0.878,95 \% \mathrm{CI}=0.723-1.066$, $\mathrm{P}=0.188$ ), distant metastasis (pooled $\mathrm{OR}=1.421$, 95\% CI $=0.885-2.282, \mathrm{P}=0.146$ ), tumor size (pooled $\mathrm{OR}=0.698,95 \% \mathrm{CI}=0.153-3.184, \mathrm{P}=0.642)$, $\mathrm{TNM}$ stage (pooled $\mathrm{OR}=0.737,95 \% \mathrm{CI}=0.474-1.147, \mathrm{P}=0.119$ ), tumor invasion (pooled $\mathrm{OR}=0.488,95 \% \mathrm{CI}=$ 0.195-1.222, $\mathrm{P}=0.126$ ), venous invasion (pooled $\mathrm{OR}=0.590,95 \% \mathrm{CI}=0.188-1.848, \mathrm{P}=0.365)$, and histologic grade (pooled $\mathrm{OR}=0.854,95 \% \mathrm{CI}=0.511-1.429$, $\mathrm{P}=0.548)$.

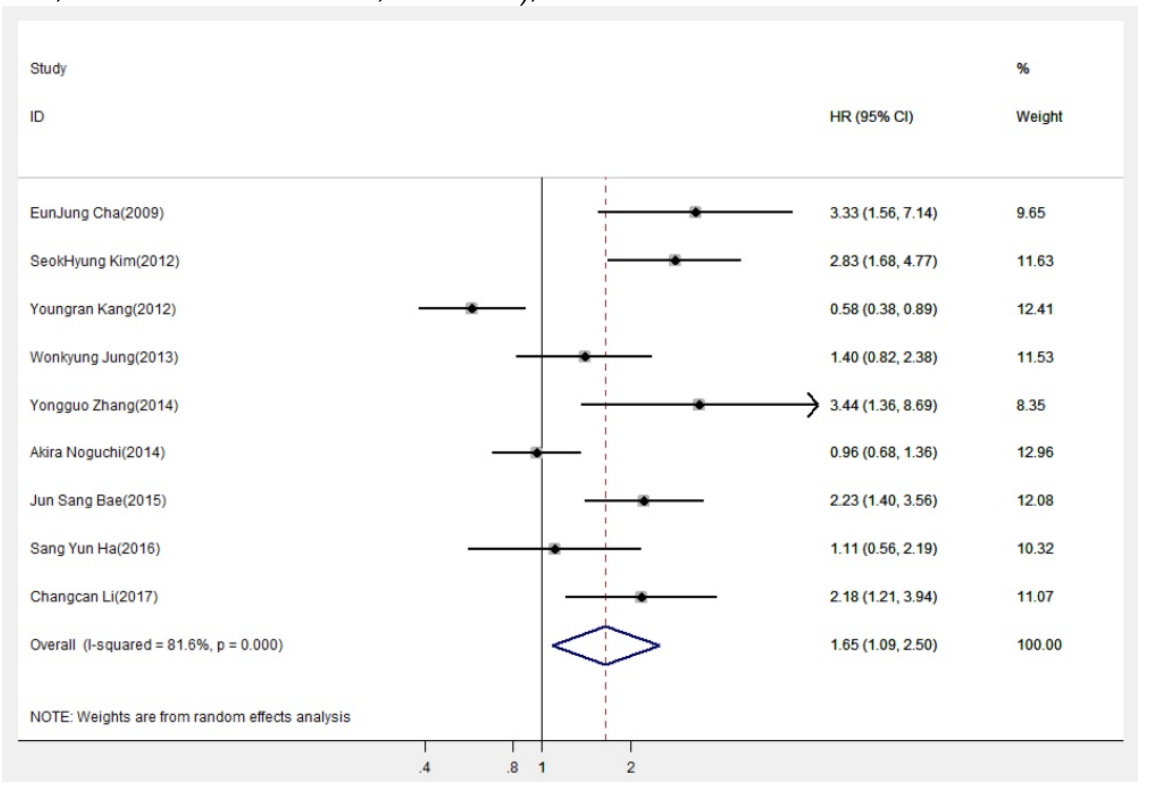

Figure 2. Forest plot of hazard ratio (HR) of overall survival (OS) for patients with digestive system cancers

Table 3. Meta-analysis of DBCl overexpression classified by clinicopathological parameters

\begin{tabular}{|c|c|c|c|c|c|c|c|}
\hline Study covariates & Studies (patients) & OR $(95 \% \mathrm{CI})$ & $I^{2}(\%)$ & $P_{\mathrm{h}}$ & $\mathbf{Z}$ & $P$ & Model \\
\hline Gender (Female/Male) & $9(2391)$ & $0.878(0.723-1.066)$ & 0.0 & 0.565 & 1.32 & 0.188 & fixed \\
\hline Age $(<60 / \geq 60)$ & $5(1121)$ & $0.596(0.467-0.761)$ & 3.5 & 0.387 & 4.14 & $<0.001$ & fixed \\
\hline WHO classification (Tubular/Others) & $2(373)$ & $3.780(2.303-6.205)$ & 0.0 & 0.348 & 5.26 & $<0.001$ & fixed \\
\hline Lauren classification (Intestinal/Diffuse) & $3(770)$ & $2.000(1.492-2.680)$ & 0.0 & 0.768 & 4.64 & $<0.001$ & fixed \\
\hline LN metastasis (Absence/Presence) & $5(1064)$ & $0.405(0.203-0.806)$ & 85.6 & $<0.001$ & 2.57 & 0.010 & random \\
\hline Distant metastasis (Absence/Presence) & $4(1270)$ & $1.421(0.885-2.282)$ & 0.0 & 0.755 & 1.45 & 0.146 & fixed \\
\hline Tumor size $(\leq 5 />5 \mathrm{~cm})$ & $2(321)$ & $0.698(0.153-3.184)$ & 85.3 & 0.009 & 0.46 & 0.642 & random \\
\hline TNM stage (1-2/3-4) & $9(2391)$ & $0.737(0.474-1.147)$ & 87.1 & $<0.001$ & 1.56 & 0.119 & random \\
\hline Tumor invasion (Early cancer/Advanced cancer) & $3(713)$ & $0.488(0.195-1.222)$ & 83.8 & 0.002 & 1.53 & 0.126 & random \\
\hline Venous invasion (Absence/Presence) & $3(921)$ & $0.590(0.188-1.848)$ & 84.8 & 0.001 & 0.91 & 0.365 & random \\
\hline $\begin{array}{l}\text { Histologic grade (well+ moderately differentiated/ } \\
\text { poorly differentiated) }\end{array}$ & $8(2192)$ & $0.854(0.511-1.429)$ & 76.2 & $<0.001$ & 0.60 & 0.548 & random \\
\hline
\end{tabular}

LN lymph node; OR odds ratio; $\mathrm{CI}$ confidence intervals; $\mathrm{Ph}$ P-value for heterogeneity based on $\mathrm{Q}$ test; $\mathrm{P}$ P-value for statistical significance based on $\mathrm{Z}$ test. 


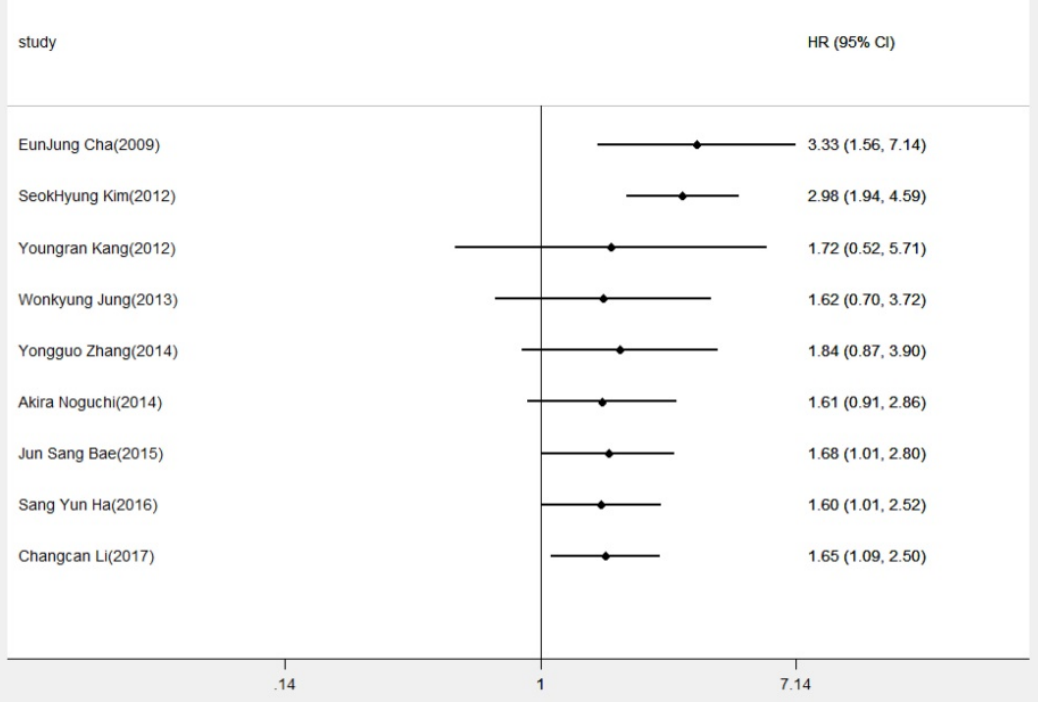

Figure 3. Cumulative meta-analysis of $\mathrm{DBCl}$ expression and $\mathrm{OS}$ in digestive system cancers

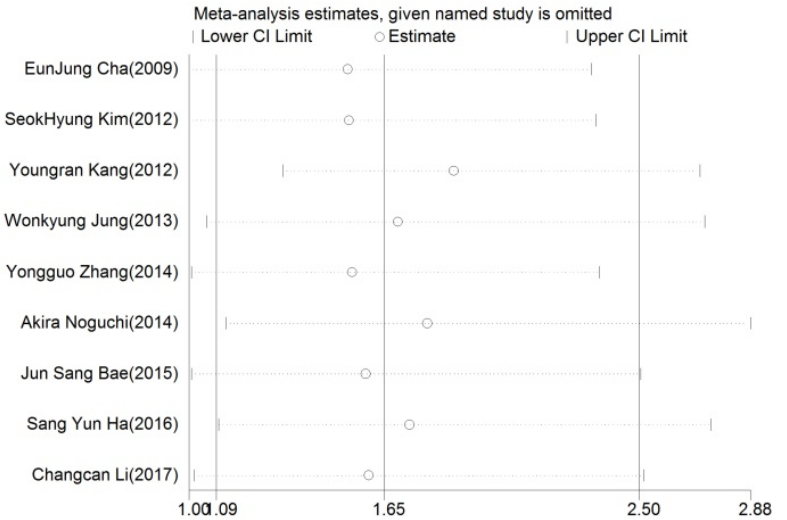

Figure 4. Sensitive analysis of overall survival (OS) for patients with digestive system cancers

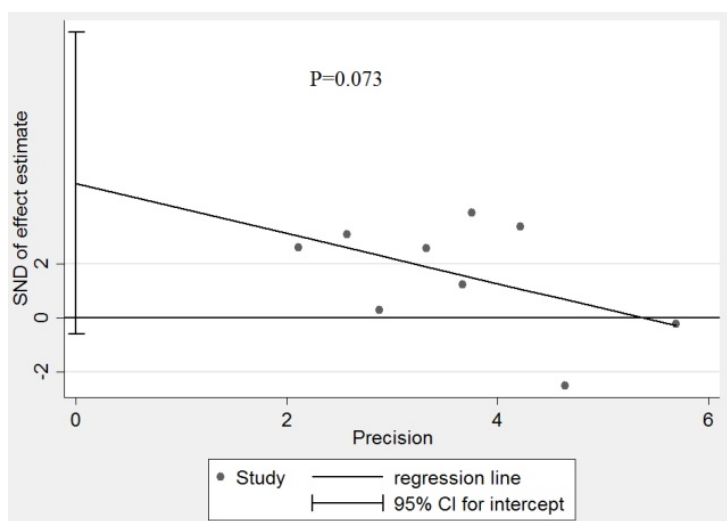

Figure 5. Effect estimate for potential publication bias of included studies in Egger' test

\section{Cumulative meta-analysis and meta-regression analysis of DBC1 expression and $O S$ in digestive system cancers}

To gain insights into the associations of DBCI expression and OS, cumulative meta-analysis was performed based on the HR for OS. As showed in Figure 3, we demonstrated that overexpression of DBC1 was regarded as an unfavorable factor of prognosis. And, with the deepening of annual research, the pooled HRs and the corresponding 95\% CIs tended to be stable and narrow. Otherwise, owing to the extreme heterogeneity among our meta-analysis, we made a further investigation in the potential source of heterogeneity by meta-regression analysis. The results revealed that cancer type $(\mathrm{P}=0.253)$, publication date $(\mathrm{P}=0.808)$, analysis method $(\mathrm{P}=0.927)$, cutoff value $(\mathrm{P}=0.526)$, sample size $(P=0.102)$, and research region $(P=0.601)$ were not responsible for the source of heterogeneity for OS.

The influence of each study on the pooled HR was evaluated by sensitivity analysis. As announced in Figure 4, no point estimate of the omitted individual dataset lay outside the $95 \%$ CI. Meanwhile, the publication bias of the included studies was evaluated through Egger's (Fig.5) and Begg's tests, the corresponding $\mathrm{P}$ value were 0.073 and 0.348 respectively. These results indicated that there was no individual study dominated the meta-analysis results, and no statistical evidence of publication bias was found for the meta-analysis. Thus, the results of this meta-analysis were stable and reliable.

\section{Discussion}

Poor prognosis is a major fatal problem after surgery for digestive system cancer, and amounts of clinical markers are being confirmed to predict patient outcome. Currently, traditional clinical and pathological parameters, including tumor size and number, tumor and venous invasion, TNM stage and LN metastasis have been considered relatively useful 
prediction [3-5]. However, great variation of prognosis was still remained in patients with digestive system cancer. In past few years, the association between molecular changes and cancer-related prognosis has been intensively explored. Biomarkers, such as long noncoding RNAs, octamer-binding transcription factor 4 , and hexokinase 2 were shown to be related to post-operation prognosis in digestive system cancer patients in corresponding metaanalysis $[6-7,26]$. This study initially revealed the importance of DBC1 expression in prognosis after surgery, suggesting that molecular biomarker would be a potential parameter for patients' outcome, thereby helping establish a better system for prognosis in patient with digestive system cancer.

It is well known that DBC1 was originally identified in a human chromosome 8 p21 region frequently deleted in breast cancers and had an indispensable role in cancer progression [27]. However, the expression level of DBC1 or its function in digestive system cancer was still controversial. On one hand, DBC1 may play an oncogenic role in tumor development. As described in the previous studies, Inhibition of the senescence of premalignant cells, regulation of SIRT1 activity, and co-activation of androgen receptor were reported to be correlation with the DBC1 expression and accelerate the tumorigenesis. It is worth noting that Hiraike et al. and Park et al. have shown that DBC1 can act as an active molecule to regulate apoptosis or transcription proteins, thus producing carcinogenic effect [9,11-12,28-29]. DBC1 expression in various cancer tissues, such as ESCC, HCC, GC, CRC, and so on, were significantly higher than in the corresponding adjacent non-tumor tissues. And, overexpression of DBC1 is significantly correlated with tumor stage, LN metastasis, tumor invasion and histological type, thereby leading to a poor prognosis [4, 18-20]. On the other hand, DBC1 potentiates suppression of SIRT1 activity, stimulates p53-dependent cell death, regulates of nuclear receptors and signaling molecules, mediates endocrine-resistant cell survival, indirectly inhibits $\mathrm{Wnt} / \beta$-catenin pathway to act as a tumor suppressor [9,14-15,17,30-33]. Likewise, Noguchi et al. reported that DBClexpression is associated with favorable outcomes [5]. In fact, the exact role of $\mathrm{DBC} 1$ in tumor progression has been rarely explored and is still controversial, which may partly due to the uncertain function of SIRT1 [9,34-35]. Meanwhile, these contradictory findings may be attributable to the different types of tumor. In view of those, we specially conducted this meta-analysis to explore the prognostic value of $\mathrm{DBC} 1$ on digestive system cancer.

In this meta-analysis, a total of 9 studies comprising 2391 patients were included in the meta-analysis, and the combined analysis showed that high level of DBC1 expression was significantly associated with unfavorable clinicopathological characteristics and reduced OS in digestive system cancers. Hence, DBC1 overexpression could be an independent marker of prognosis in patients with digestive system cancer. Moreover, we conducted a cumulative meta-analysis to explore the variation trend of the combined effect based on the chronological order, the result confirmed the stable trend of significant association between $\mathrm{DBC} 1$ and $\mathrm{OS}$ as time accumulated. In sensitivity analysis and bias tests, no individual study dominated the results, and no publication bias was found for the meta-analysis, suggested the robustness of the present meta-analysis. However, heterogeneity is an important reference factor for meta-analysis, forest plots and $\mathrm{I}^{2}$ showed that the extreme heterogeneity based on the HR for OS were significantly detected among the included studies. Thus, stratified analysis were performed, and significant heterogeneity were yielded in most of subgroups on the basis of analysis method, publication date, cutoff value, sample size, cancer type and research region. Such significant heterogeneity could be probably due to the diversity in the gender, ethnicity, regional, cancer types, sample size, research method, and literature quality. Subsequent metaregression analysis was used to determine the possible causes of the heterogeneity. However, the results revealed $\mathrm{P}$ values more than 0.05 in all specified covariates, indicating that none of the factors was responsible for the source of heterogeneity for OS. Otherwise, stratified analysis also verified the potential prognostic prediction of $\mathrm{DBC} 1$ in subgroups, prognosis significance of DBC1 expression in digestive system cancers was found in subgroups of analysis method (univariate analysis), publication date ( $\leq 5$ years), cutoff value (positive tumor cells $>50 \%)$, sample size $(<200)$, cancer type (digestive tract cancer), and research region (China). However, the pooled results were not statistically significant in other corresponding subgroups, especially in identical cancer type subgroups. Since SIRT1 was reported participate in tumor progression as both a tumor promoter and a tumor suppresser [34-35]. DBC1 as a negative regulator of SIRT1 [9], may also participate in both tumor promotion and tumor suppression. Also, the expression and function of DBC1 within various malignancies were not yet confirmed. And, the cutoff scores for DBC1 expression in present studies are significant incongruity $[4,22$ ,36-37]. Despite there was no critical error in our data extraction and statistical analysis, the phenomena described above may lead to differences in results. 
Therefore, more study in appropriate cohorts of patients with well-designed study protocol for exploring the prognostic effect of $\mathrm{DBC} 1$ on digestive system cancers are urgent required.

Considering the clinicopathological factors that have been already confirmed to be related to tumor progression and patient's prognosis [3-5], further study should be carried out on its correlation with DBC1 expression. Pooled ORs for the age, WHO classification, Lauren classification, and LN metastasis were statistically significant in the correlation study of DBC1 expression with the clinical characteristics of patients. However, some of the clinicopathological factors, such as distant metastasis, Tumor size, TNM stage, tumor invasion, venous invasion, and histologic grade, which have been documented to be the major factors in tumor development, were not related to the expression of DBC1 in our meta-analysis. It is quite agree with the results from stratified survival analysis of DBC1 expression in digestive system cancers, DBC1 might not only promote tumor growth, but also inhibits the process of tumor [28-33]. Interestingly, LN metastasis is the most common mode of metastasis of digestive system cancers, positive LN metastasis was proved to be an active factor in tumor progression and influence the prognosis of patients [38-41], which is consistent with the studies in DBC1 expression and disease-free survival [3,18-20,25]. Previous studies have not yet found that cancer-related proteins share the same histological characteristics between different cancer tissues, but the response to cancer cells is likely to be consistent. Herein, overexpression of DBC1 could stimulate the LN metastasis and leads to tumor metastasis and tumor recurrence, thereby contributing to poor prognosis in patients with digestive system cancers.

Immunoreactivity for DBC1 was found primarily in the nuclei. With regard to digestive system cancers, studies on the expression of DBC1 in tissues have shown unambiguous results, it is mainly discovered that $\mathrm{DBC} 1$ expression was significantly up-regulated in cancer tissues compared to adjacent normal tissues [3-5,18-22]. Currently, several studies have revealed that $\mathrm{DBC} 1$ is essential for cell proliferation, apoptosis and histone modification, all crucial for regulating tumorigenesis[42-43]. Besides, huge number of papers refers to the functions of DBC1 as a negative regulator of SIRT1, inhibition of SIRT1 function could induce growth arrest or apoptosis of human cancer cells $[9,44-45]$. DBC1, as a natural negative regulation of the deacetylase SIRT1, might be increased to compensate for up-regulated SIRT1 activity in patients with cancer [19]. Furthermore, knockdown of DBC1 significantly inhibited cell growth and cancer cell clonogenicity [20]. Thus, for the remarkable performance of $\mathrm{DBC} 1$ in tumorigenesis and prognosis, DBC1 might be a crucial therapeutic target in patients with digestive system cancers.

The limitations of this meta-analysis should be mentioned. First, only 9 studies were included in our quantitative analysis. Most studies did not report the subsequent therapy after surgical treatment that might affect the certainty of patients' prognosis, which may be a potential confounding factor of heterogeneity. Secondly, the studies have subjects of different age, follow-up time, and cut-off values, as the consensus value were rather difficult to reach, heterogeneity may be inevitably brought in. Thirdly, studies were of Asian origin and none of the included study was published this year, impeding the applicability and timeliness of the results across different ethnicities. Fourth, despite our efforts to make a comprehensive analysis, there were still 2 studies' HRs and the corresponding 95\% CIs directly from univariate analysis, which would affect the validity of survival analysis for overall OS in digestive system cancers. Fifth, due to the small number of included studies, we neither found the association between DBC1 expression and digestive system cancers in subgroup analysis based on various categories, nor investigated about the role of proteins related to DBC1. Thus, more large-scale studies in different ethnicities with longer follow-up and much scientific protein expression cut off value are needed to further investigate the relationship of DBC1 to the prognosis of digestive system cancer.

In conclusion, this meta-analysis showed that high $\mathrm{DBC1}$ expression may be related to the poor survival, old age, and positive LN metastasis in patients with digestive system cancers. Additionally, DBC1 could not only be an independent prognostic factor for survival of patients with digestive system cancer, but might also be a novel target for cancer therapy. For the limitations of the present study, more relevant studies are eagerly warranted.

\section{Abbreviations}

ESCC: Esophageal squamous cell carcinoma; GC: gastric cancer; HCC: hepatocellular carcinoma; CRC: colorectal cancer; LN: lymph node; DBC1/CCAR2: Deleted in breast cancer-1/Cell Cycle and Apoptosis Regulator 2; OS: overall survival; HRs: hazard rations; CIs: confidence intervals; NOS: Newcastle-Ottawa Scale; ORs: odds ratios.

\section{Acknowledgments}

Conception and experimental design: Jingting Liu, Chunyan Meng, and Jianhua Liao. Data retrieval: Chunyan Meng, Changcan Li, Kaifeng Tang, and Hongchao Tang. Data analysis: Jingting Liu, Chang- 
can Li, Hongchao Tang, and Jianhua Liao. Interpretation of the results: Jingting Liu, Chunyan Meng, Changcan Li, and Jianhua Liao. Paper writing: Jingting Liu, Chunyan Meng, and Jianhua Liao.

\section{Competing Interests}

The authors have declared that no competing interest exists.

\section{References}

1. Bosman FT, Carneiro F, Hruban RH, et al. WHO classification of tumours of the digestive system/. International Agency for Research on Cancer. 2010:1089.

2. Torre LA, Bray F, Siegel RL, et al. Global cancer statistics, 2012. Ca A Cancer Journal for Clinicians. 2015; 65(2):87-108

3. Bae JS, Park SH, Kim KM, et al. CK2a phosphorylates DBC1 and is involved in the progression of gastric carcinoma and predicts poor survival of gastric carcinoma patients. International Journal of Cancer. 2015; 136(4):797-809.

4. Zhang Y, Gu Y, Sha S, et al. DBC1 is over-expressed and associated with poor prognosis in colorectal cancer. International Journal of Clinical Oncology. 2014; 19(1):106-112.

5. Noguchi A, Kikuchi K, Zheng H, et al. SIRT1 expression is associated with a poor prognosis, whereas DBC1 is associated with favorable outcomes in gastric cancer. Cancer Medicine. 2014; 3(6):1553-1561.

6. $\mathrm{Wu} \mathrm{J}, \mathrm{Hu} \mathrm{L}, \mathrm{Hu} \mathrm{F}$, et al. Poor prognosis of hexokinase 2 overexpression in solid tumors of digestive system: a meta-analysis. Oncotarget. 2017; 8(19): 32332-32344.

7. Chen Z, Zhang L, Zhu Q, et al. Clinical value of octamer-binding transcription factor 4 as a prognostic marker in patients with digestive system cancers: A systematic review and meta-analysis. Journal of Gastroenterology \& Hepatology. 2017; 32(3):567-576

8. Hamaguchi M, Meth JL, Von $\mathrm{KC}$, et al. DBC2, a candidate for a tumor suppressor gene involved in breast cancer. Proceedings of the National Academy of Sciences of the United States of America. 2002; 99(21):13647-13652.

9. Zhao W, Kruse JP, Tang Y, et al. Negative regulation of the deacetylase SIRT1 by DBC1. Nature. 2008; 451(7178):587-590.

10. Lee H, Kim KR, Noh SJ, et al. Expression of DBC1 and SIRT1 is associated with poor prognosis for breast carcinoma. Human Pathology. 2011; 42(2):204-213.

11. Hiraike $\mathrm{H}$, Wadahiraike $\mathrm{O}$, Nakagawa $\mathrm{S}$, et al. Identification of $\mathrm{DBC} 1$ as a transcriptional repressor for BRCA1. British Journal of Cancer. 2010; 102(6):1061-1067.

12. Park SH, IV PR, Frisch SM. Regulation of anoikis by deleted in breast cancer-1 (DBC1) through NF-kB. Apoptosis, 2013; 18(8):949-962

13. Kim JE, Chen J, Lou Z. p30 DBC is a potential regulator of tumorigenesis. Cell Cycle. 2009; 8(18):2933-2936.

14. Trauernicht AM, Kim SJ, Kim NH, et al. DBC-1 mediates endocrine resistant breast cancer cell survival. Cell Cycle. 2010; 9(6):1218-1219.

15. Trauernicht AM, Kim SJ, Kim NH, et al. Modulation of estrogen receptor alpha protein level and survival function by DBC-1. Molecular Endocrinology. 2007; 21(7):1526-1536.

16. Huan $\mathrm{Y}, \mathrm{Wu} \mathrm{D}, \mathrm{Zhou} \mathrm{D}$, et al. DBC1 promotes anoikis resistance of gastric cancer cells by regulating NF-kB activity. Oncology Reports. 2015; 34(2):843-849.

17. Yu EJ, Kim SH, Kim HJ, et al. Positive regulation of $\beta$-catenin-PROX1 signaling axis by DBC1 in colon cancer progression. Oncogene. 2015; 35(26):3410-3418.

18. Kim $\mathrm{SH}, \mathrm{Kim} \mathrm{JH}, \mathrm{Yu}$ EJ, et al. The overexpression of DBC1 in esophageal squamous cell carcinoma correlates with poor prognosis. Histology \& Histopathology. 2012; 27(1):49-58.

19. Cha EJ, Noh SJ, Kwon KS, et al. Expression of DBC1 and SIRT1 is associated with poor prognosis of gastric carcinoma. Clinical Cancer Research An Official Journal of the American Association for Cancer Research. 2009; 15(13):4453-4459.

20. Li C, Liao J, Wu S, et al. Overexpression of DBC1, correlated with poor prognosis, is a potential therapeutic target for hepatocellular carcinoma. Biochemical \& Biophysical Research Communications. 2017; 494(3-4):511-517.

21. Kang Y, Jung WY, Lee $H$, et al. Expression of SIRT1 and DBC1 in Gastric Adenocarcinoma. Korean journal of pathology. 2012; 46(6):523-531.

22. Jung W, Hong KD, Jung WY, et al. SIRT1 Expression Is Associated with Good Prognosis in Colorectal Cancer. Korean Journal of Pathology. 2013; 47(4):332-339.

23. Tierney JF, Stewart LA, Ghersi D, et al. Practical methods for incorporating summary time-to-event data into meta-analysis. Trials. 2007; 8(1):16.

24. Stang A. Critical evaluation of the Newcastle-Ottawa scale for the assessment of the quality of nonrandomized studies in meta-analyses. European Journal of Epidemiology. 2010; 25(9):603-605.

25. Sang YH, Kim JH, Yang JW, et al. Expression of DBC1 is associated with poor prognosis in hepatitis virus-related hepatocellular carcinoma. Pathology Research \& Practice. 2016; 212(7):616-621.
26. Zheng $\mathrm{C}, \mathrm{Hao} \mathrm{H}$, Chen $\mathrm{L}$, et al. Long noncoding RNAs as novel serum biomarkers for the diagnosis of hepatocellular carcinoma: a systematic review and meta-analysis. Clinical \& Translational Oncology. 2017; 19:1-8.

27. Joshi P, Quach OL, Giguere SS, et al. A Functional Proteomics Perspective of DBC1 as a Regulator of Transcription. Journal of proteomics \& bioinformatics. 2013; (Suppl 2):002.

28. Li Z, Chen L, Kabra N, et al. Inhibition of SUV39H1 Methyltransferase Activity by DBC1. Journal of Biological Chemistry. 2009; 284(16):10361-10366.

29. Park HS, Bae JS, Noh SJ, et al. Expression of DBC1 and Androgen Receptor Predict Poor Prognosis in Diffuse Large B Cell Lymphoma. Translational Oncology. 2013; 6(3):370-381.

30. Zannini L, Buscemi G, Kim JE, et al. DBC1 phosphorylation by ATM/ATR inhibits SIRT1 deacetylase in response to DNA damage. Journal of Molecular Cell Biology. 2012; 4(5):294-303.

31. Fu J, Jiang J, Li J, et al. Deleted in breast cancer 1, a novel androgen receptor (AR) coactivator that promotes AR DNA-binding activity. Journal of Biological Chemistry. 2009; 284(11):6832-6840.

32. Nin V, Escande C, Chini CC, et al. Role of Deleted in Breast Cancer 1 (DBC1) Protein in SIRT1 Deacetylase Activation Induced by Protein Kinase A and AMP-activated Protein Kinase. Journal of Biological Chemistry. 2012; 287(28):23489-23501.

33. Ragusa S, Cheng J, Ivanov KI, et al. PROX1 promotes metabolic adaptation and fuels outgrowth of Wnt(high) metastatic colon cancer cells. Cell Reports. 2014; 8(6):1957-1973.

34. Yuan J, Minterdykhouse K, Lou Z. A c-Myc-SIRT1 feedback loop regulates cell growth and transformation. Journal of Cell Biology, 2009; 185(2):203-211.

35. Kabra N, Li Z, Chen L, et al. SirT1 is an inhibitor of proliferation and tumor formation in colon cancer. Journal of Biological Chemistry. 2009; 284(27):18210-18217

36. Won KY, Cho H, Kim GY, et al. High DBC1 (CCAR2) expression in gallbladder carcinoma is associated with favorable clinicopathological factors. International Journal of Clinical \& Experimental Pathology. 2015; 8(9):11440-11445.

37. Kikuchi K, Noguchi A, Takahashi H, et al. High SIRT1 expression and low DBC1 expression are associated with poor prognosis in colorectal cancer. Journal of Cancer Therapeutics \& Research. 2013; 2(1):1-7.

38. Nakanishi Y. Histopathologic Findings Predicting Lymph Node Metastasis and Prognosis of Patients with Superficial Esophageal Carcinoma[M]// Superficial Esophageal Neoplasm. Springer Japan, 2002:1285-1293.

39. Yamao $\mathrm{T}$, Shirao $\mathrm{K}$, Ono $\mathrm{H}$, et al. Risk factors for lymph node metastasis from intramucosal gastric carcinoma. Cancer. 1996; 77(4):602-606.

40. Kitajima K, Fujimori T, Fujii S, et al. Correlations between lymph node metastasis and depth of submucosal invasion in submucosal invasive colorectal carcinoma: a Japanese collaborative study. Journal of Gastroenterology. 2004; 39(6):534-543.

41. Xiaohong S, Huikai L, Feng W, et al. Clinical significance of lymph node metastasis in patients undergoing partial hepatectomy for hepatocellular carcinoma. World Journal of Surgery. 2010; 34(5):1028-1033.

42. Anantharaman V, Aravind L. Analysis of DBC1 and its homologs suggests a potential mechanism for regulation of sirtuin domain deacetylases by NAD metabolites. Cell Cycle, 2008; 7(10):1467-1472.

43. Kuzmichev A1, Margueron R, Vaquero A, et al. Composition and histone substrates of polycomb repressive group complexes change during cellular differentiation. Proceedings of the National Academy of Sciences of the United States of America, 2005; 102(6):1859-1864.

44. Ota $\mathrm{H}$, Tokunaga $\mathrm{E}$, Chang $\mathrm{K}$, et al. Sirt1 inhibitor, Sirtinol, induces senescence-like growth arrest with attenuated Ras-MAPK signaling in human cancer cells. Oncogene, 2006; 25(2):176-185.

45. Sun Y, Sun D, Li F, et al. Downregulation of Sirt1 by antisense oligonucleotides induces apoptosis and enhances radiation sensitization in A549 lung cancer cells. Lung Cancer, 2007; 58(1):21-29. 